\title{
The calculate of current transformers with combined magnetic cores
}

\author{
Andrey Batrashov ${ }^{1, *}$, and Olga Stepanskaya ${ }^{2}$ \\ ${ }^{1}$ Ural State University of Railway Transport, Kolmogorova St., 66, 620034 Ekaterinburg, Russia \\ ${ }^{2}$ Emperor Alexander I St. Petersburg State Transport University, 9 Moskovsky pr., 190031 Saint \\ Petersburg, Russia
}

\begin{abstract}
The manufacture of current transformers is associated with many design constraints, which include the restricted dimensions of its installation places, requirements for the accuracy class, as well as the limitation on the safety factor or the minimum factor of the accuracy limit factor. In a design sense of current transformers, these requirements are contradictory, which resulting in a flexible approach to the manufacture of current transformers. The use of combined magnetic cores can be referred to one of these areas, in other words magnetic cores consisting of materials with different magnetic properties, which allows to obtain unique magnetic properties that are inaccessible when using magnetic cores of the same type (material), thus providing a rational model of production. The article presents a feature of calculating of current transformer with combined magnetic cores.
\end{abstract}

\section{Introduction}

Current transformers became widely used for current measurement in high-voltage installations. The standards $[1,2]$ indicate the basic requirements for current transformers. In the present article, special attention is given to the approach to the calculating of the current and angular error, as well as the safety factor for the measuring windings in the case of the combined execution of the magnetic core on the current transformer. Particular attention is given to the appliance of nanocrystalline materials for magnetic cores [3-5].

The appliance actuality of combined magnetic cores for current transformers consists in the possibility of obtaining measuring transformers with a high accuracy class at a minimum cost, mass and, accordingly, dimension [6]. The latter requirement is often determinative due to the limited space for installing a set of current transformers at the outputs of breakers, supply transformers, and the like devices.

Also, no less important limitation in the design of measuring transformers is the requirement for the safety factor, that is, the multiplicity of the secondary current of the transformer while an increase of the primary current from overloads and short circuits.

Thus, the designer is in search of the optimal mass and dimension parameters of the magnetic core, at which the required accuracy class is ensured (usually this is most actual for accuracy classes $0.2 \mathrm{~S}$ and $0.5 \mathrm{~S}$ intended for fiscal electricity metering), and the safety

\footnotetext{
* Corresponding author: ABatrashov@usurt.ru
} 
factor of the instruments is not exceeded: the larger the magnetic core section, the lower the current and angular error, but at the same time, the safety factor of the measuring winding instruments increases in direct proportion to the section.

\section{Materials and methods}

The structural design of a current transformer depends on the requirements that are imposed on it concerning the installation place, the required accuracy class, primary current, voltage level in the primary winding, etc. Let's highlight the dominant requirements that have a direct impact on the calculation of the error of the current transformer, as well as the safety factor.

The following data serves as the initial data for the calculation while designing of current transformers:

1) the number of taps and their nominal primary currents $I_{1}$ nom, A;

2) nominal current of secondary winding $I_{2}$ nom, A;

3) frequency $f, \mathrm{~Hz}$;

4) required accuracy class;

5) nominal load $S_{2}$ nom, BA;

6) load power factor $\cos \varphi_{2}$;

7) length of taps of conductors, $m$

8) limiting overall dimensions: inner and outer diameters, height.

The overwhelming majority of internal current transformers are performed for the case of one turn of the primary winding $w_{1}$. Generically the number of turns of the secondary winding $w_{2}$ is calculated by the formula

$$
w_{2}=\frac{I_{1} w_{1}}{I_{2}} .
$$

In accordance with GOST 7746-2015 the power coefficient of nominal secondary load is set equal to $\cos \varphi_{2}=0,8$. The active $R_{\mathrm{H}}$ and reactive $X_{\mathrm{H}}$ resistance of secondary load can be determined from the formulas

$$
\begin{gathered}
R_{\mathrm{H}}=\frac{S_{\text {2ном }} w_{2}}{I_{2}{ }^{2}} \cos \varphi_{2} ; \\
X_{\mathrm{H}}=\frac{S_{2 \text { ном }} w_{2}}{I_{2}{ }^{2}} \sqrt{1-\cos \varphi_{2}{ }^{2}} .
\end{gathered}
$$

The resistance of the secondary winding wire is added to the resistance of the measuring instruments, which is calculated by the formulas

$$
\begin{gathered}
R_{2 \text { обм }}=\frac{4\left(\rho_{\text {обм }} w_{2}\left(d_{\text {н }}-d_{\text {вн }}+2 h_{\text {и }}\right) k_{\text {обм }}\right)}{\pi d_{2}^{2}} ; \\
X_{2 \text { обм }}=4 \pi 10^{-7} f w_{2}{ }^{2} h_{\text {и }} \ln \left(\frac{d_{\text {н }}}{d_{\text {вн }}}\right),
\end{gathered}
$$

where $\rho_{\text {obm }}$ - volume resistivity of secondary winding wire, ohmmeter; $d_{\text {out }}$ and $d_{\text {in }}$ - outer and inner diameters of the magnetic core, taking into account insulation, $\mathrm{m} ; h_{\mathrm{i}}-$ the height 
of the magnetic core, taking into account insulation, $\mathrm{m} ; k_{\mathrm{obm}}-$ the height of the magnetic core, taking into account insulation, $\mathrm{m} ; d_{2}$ - diameter of the secondary winding wire, $\mathrm{m}^{2} ; f-$ current frequency, $\mathrm{Hz}$.

The resistance of the offtake wires is added to the resistance of the coil winding

$$
\begin{gathered}
R_{\text {отв }}=\frac{2 \rho_{\text {отв }} l_{\text {отв }}}{S_{\text {отв }}} ; \\
X_{\text {отв }}=\mu_{0} f l_{\text {отв }}\left(\ln \frac{2 l_{\text {отв }}}{r_{\text {отв }}}-\frac{3}{4}\right),
\end{gathered}
$$

where $\mu_{0}$ - vacuum permeability equal to $4 \pi \cdot 10^{-7} \mathrm{H} / \mathrm{m} ; \rho_{\text {otv }}$ - volume resistivity of tap leads, ohmmeter; $l_{\text {otv }}$ - the length of the offtake wires, $\mathrm{m} ; r_{\mathrm{otv}}$ - cross-sectional view radius of tap leads, m.

The phase displacement angle, taking into account the load, secondary winding and tap leads, is determined from the formula

$$
\psi=\arctan \frac{X_{\mathrm{H}}+X_{2 \text { обм }}+X_{\text {отв }}}{R_{\mathrm{H}}+R_{2 \text { обм }}+R_{\text {отв }}} .
$$

The induction in the magnetic core at the nominal operating conditions is determined from the formula

$$
B_{\text {ном }}=\frac{I_{2}\left(R_{\mathrm{H}}+R_{2 \text { обм }}+R_{\text {отв }}\right)}{\sqrt{2} \pi w_{2} f S_{\mathrm{M}} \cos \psi},
$$

Dependences of the magnetic permeability of the magnetic core $\mu$ and the magnetic loss angle $\alpha$ on the induction $B_{m}$ is shown in Fig. 1. Specified characteristics available from experience with the help of measuring the magnetic properties in laboratory conditions. Thus, the values of a function that is set table-like can be found using interpolation. The method of piecewise linear approximation according to the method of cubic spline was used in this search.

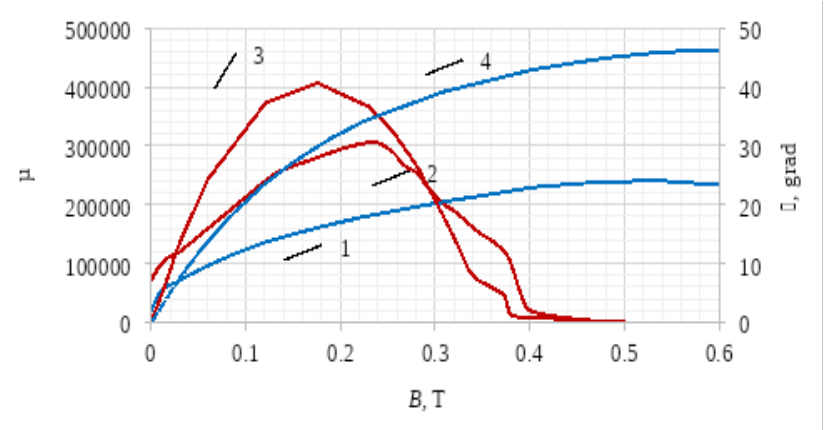

Fig. 1. Magnetic materials characterization depending upon the magnetic induction $B: 1$ - magnetic permeability $\mu$ of the magnetic core of the AMET-82B type; 2 - magnetic permeability $\mu$ of the magnetic core of the AMET-5B type; 3 - magnetic loss angle $\alpha$ of the magnetic core of the AMET82B type; 4 - magnetic loss angle $\alpha$ of the magnetic core of the AMET-5B type.

The magnetic field strength $H_{m}$ and magnetizing current $I_{0}$ are determined from the following formulas 


$$
\begin{gathered}
H_{m}=\frac{B_{m}}{\mu_{0} \mu} ; \\
I_{0}=\frac{\pi D_{\mathrm{cp}} H_{m}}{\sqrt{2} w_{1}},
\end{gathered}
$$

where $D_{\text {mid }}$ - mid line of the magnetic core, $\mathrm{m}$.

Calculation of the angular error $\delta$ of current transformer (per minutes) and current error $\Delta K$ (on a percentage base) are determined from the formulas

$$
\begin{gathered}
\delta=\arctan \left(\frac{I_{0} \cos (\alpha+\psi)}{I_{2} w_{2} / w_{1}+I_{0} \sin (\alpha+\psi)}\right) \cdot \frac{60 \cdot 180}{\pi} \\
\Delta K=\left(I_{2} w_{2} / w_{1}-\frac{I_{0} \cos (\alpha+\psi)}{\sin (\delta)}\right) \cdot \frac{100}{w_{1} I_{1} / I_{1 \text { ном }}} .
\end{gathered}
$$

A feature of the calculation of current transformers with combined magnetic cores is that the magnetic behavior of materials makes its contribution in direct ratio to the fraction of the cross-section that it occupy in the magnetic core (Fig. 2). It can be seen from the figure that the magnetic cores can be combined in height or diameter. As practice shows, option (b) of the combination in height is the most technologically simple from the point of view of production, therefore, we will consider the calculation of equivalent characteristics in this case.

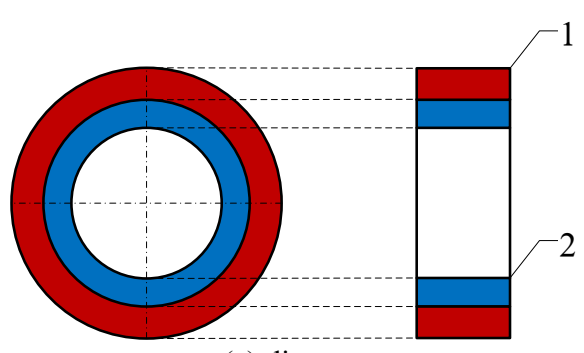

(a) diameter

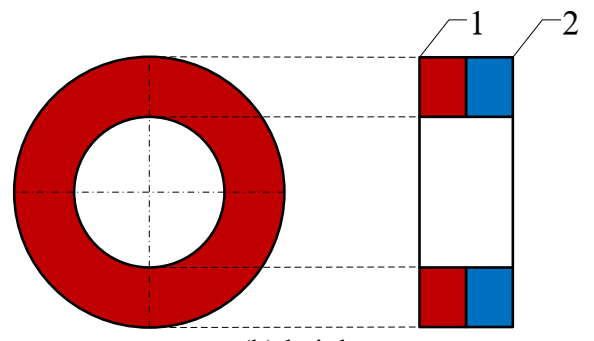

(b) height

Fig. 2. Methods of combination of magnetic cores: 1 - the magnetic core of AMET-82B type; 2 - the magnetic core of AMET-5B type.

Equivalent characteristics $\alpha_{\text {equ }}\left(B_{m}\right)$ and $\mu_{\text {equ }}\left(B_{m}\right)$ of magnetic core combined in height are determined from the following formulas

$$
\begin{aligned}
& \alpha_{\text {экВ }}\left(B_{m}\right)=\frac{\alpha_{1}\left(B_{m}\right) h_{1}+\alpha_{2}\left(B_{m}\right) h_{2}}{h_{1}+h_{2}} ; \\
& \mu_{\text {экв }}\left(B_{m}\right)=\frac{\mu_{1}\left(B_{m}\right) h_{1}+\mu_{2}\left(B_{m}\right) h_{2}}{h_{1}+h_{2}}
\end{aligned}
$$

where $h_{1}$ and $h_{2}$ - heights of the magnetic cores of 1 and 2 types, respectively, m; $\alpha_{1}\left(B_{m}\right)$ and $\alpha_{2}\left(B_{m}\right)$ - dependence of magnetic loss angle on magnetic induction for the magnetic cores of 1 and 2 types, respectively, grad; $\mu_{1}\left(B_{m}\right)$ and $\mu_{2}\left(B_{m}\right)$ - dependence of relative 
magnetic permeability on magnetic induction for the magnetic cores of 1 and 2 types, respectively.

The presented calculation method was verified in laboratory conditions with the use of the KNT-05 comparator and showed good convergence of the calculation results and measurement results. The characteristics of the magnetic cores were taken using an FT-01 ferrotest. Applicable for stationary calculations. To calculate the dynamics of transient processes, the complicating of the calculation model is required, as shown in $[7,8]$.

\section{Results and discussion}

Let's consider current transformer design with an accuracy class of $0.2 \mathrm{~S}$ with the following required characteristics: nominal primary current $I_{1 \text { nom }}-400 \mathrm{~A}$ and $600 \mathrm{~A}$; nominal current of secondary winding $I_{2 \text { nom }}-5 \mathrm{~A}$; nominal load $S_{2 \text { nom }}-20 \mathrm{BA}$ (for tap $400 \mathrm{~A}$ ) and $40 \mathrm{BA}$ (for tap $600 \mathrm{~A}$ ); the maximum safety factor -5 ; the minimum internal diameter $d_{\text {in }}-320$ $\mathrm{mm}$; the maximum outside diameter $d_{\text {out }}-510 \mathrm{~mm}$; maximum height $h_{\mathrm{i}}-100 \mathrm{~mm}$; the length of the taps wires $-8.5 \mathrm{~m}$.

Let's calculate the current transformer with the combined magnetic core of AMET5B:82B type 1:1. The split 1:1 shows that the cross-sectional areas of the components of the magnetic core are equal. The size of the magnetic core $d_{\text {in }} \times d_{\text {out }} \times h$ is as follows: $345 \times 445 \times 40 \mathrm{~mm}$. With the same diameters, the heights $h_{1}$ and $h_{2}$ will be $20 \mathrm{~mm}$ each.

The calculation is carried out according to the formulas presented in Section 2. At the same time, it was count of the fact that the current error can be easily corrected with the help of the turns correction technology.

Turns correction is carried out by winding operation of an additional winding with the number of turns one less than that of the main one. Changing in cross-section of the winding of the turns correction allows to obtain a fractional turns correction on the equivalent winding (not an integer number of turns). This technology makes it possible to reduce the magnetic core section without detriment to the measurement accuracy; therefore, it was automatically applied in the calculation.

The results of calculating the current and angular errors are summarized in Table 1. For comparison, the table also shows the results of calculating a current transformer using magnetic cores of the AMET-5B and AMET-82B types.

Table 1. Results of calculating the current transformer (with turns correction).

\begin{tabular}{|c|c|c|c|c|c|c|c|c|c|c|c|}
\hline \multirow{2}{*}{\multicolumn{5}{|c|}{$\frac{\text { 1) combined magnetic core }(345 \times 445 \times 41}{\text { Tee off } 400 \mathrm{~A}}$}} & mm) & vpe of $A$ & ИЕT-5B: & 2B 1:1 & & & \\
\hline & & & & & \multicolumn{5}{|c|}{ Tee off $600 \mathrm{~A}$} & \multicolumn{2}{|c|}{ Request } \\
\hline $\begin{array}{l}I_{1} \\
\%\end{array}$ & $B_{m}, \mathrm{~T}$ & $\mu$ & $\begin{array}{c}\Delta K \\
\%\end{array}$ & $\begin{array}{c}\delta \\
\min \end{array}$ & $\begin{array}{l}I_{1}, \\
\%\end{array}$ & $B_{m}, \mathrm{~T}$ & $\mu$ & $\begin{array}{c}\Delta K \\
\%\end{array}$ & $\begin{array}{c}\delta \\
\min \end{array}$ & $\begin{array}{c}\Delta K, \\
\%\end{array}$ & $\begin{array}{c}\delta \\
\min \end{array}$ \\
\hline 1 & 0.002 & 51,788 & $\overline{0} \cdot \overline{23}$ & 18.58 & 1 & 0.002 & 53,290 & $-\overline{2}$ & 14.46 & 0.75 & 30 \\
\hline 5 & 0.009 & 72,588 & $\begin{array}{c}- \\
0.16 \\
\end{array}$ & 12.94 & 5 & 0.011 & 77,036 & $\begin{array}{c}- \\
0.15 \\
\end{array}$ & 9.66 & 0.35 & 15 \\
\hline 20 & 0.037 & 102,842 & $\begin{array}{c}- \\
0.13 \\
\end{array}$ & 8.05 & 20 & 0.046 & 112,389 & $-\overline{1}$ & 5.56 & 0.2 & 10 \\
\hline 50 & 0.093 & 160,971 & $\begin{array}{c}- \\
0.08 \\
\end{array}$ & 4.00 & 50 & 0.115 & 182,379 & $\begin{array}{c}- \\
0.07 \\
\end{array}$ & 2.42 & 0.2 & 10 \\
\hline 100 & 0.185 & 225,229 & $\overline{-}-$ & 2.11 & 100 & 0.229 & 243,312 & $-\overline{0}$ & 1.44 & 0.2 & 10 \\
\hline 120 & 0.222 & 241,123 & $-\overline{0}$ & 1.95 & 120 & 0.275 & 227,032 & $\begin{array}{c}- \\
0.05\end{array}$ & 1.74 & 0.75 & 30 \\
\hline \multicolumn{5}{|c|}{ Safety factor $=5$} & \multicolumn{5}{|c|}{ Safety factor $=4$} & \multicolumn{2}{|c|}{5} \\
\hline \multicolumn{12}{|c|}{ Approximate price of current transformer $=2,160$ USD } \\
\hline \multicolumn{12}{|c|}{ 2) magnetic core $(345 \times 445 \times 40 \mathrm{~mm})$ type of AMET-5B } \\
\hline \multicolumn{5}{|c|}{ Tee off $400 \mathrm{~A}$} & \multicolumn{5}{|c|}{ Tee off $600 \mathrm{~A}$} & \multicolumn{2}{|c|}{ Request } \\
\hline
\end{tabular}


Table 1. Continued.

\begin{tabular}{|c|c|c|c|c|c|c|c|c|c|c|c|}
\hline $\begin{array}{l}I_{1}, \\
\%\end{array}$ & $B_{m}, \mathrm{~T}$ & $\mu$ & $\begin{array}{l}\Delta K, \\
\%\end{array}$ & $\begin{array}{c}\delta, \\
\min \end{array}$ & $\begin{array}{l}I_{1}, \\
\%\end{array}$ & $B_{m}, \mathrm{~T}$ & $\mu$ & $\begin{array}{c}\Delta K, \\
\%\end{array}$ & $\begin{array}{c}\delta, \\
\min \end{array}$ & $\begin{array}{l}\Delta K, \\
\%\end{array}$ & $\begin{array}{c}\delta \\
\min \end{array}$ \\
\hline 1 & 0.002 & 27,632 & $\overline{0.43}$ & 34.61 & 1 & 0.002 & 29,313 & 0.39 & 26.23 & 0.75 & 30 \\
\hline 5 & 0.009 & 49,342 & $0 . \overline{19}$ & 19.08 & 5 & 0.011 & 53573 & $\overline{0} \overline{18}$ & 14.01 & 0.35 & 15 \\
\hline 20 & 0.037 & 76,811 & $\overline{0.11}$ & 11.28 & 20 & 0.046 & 84,362 & $\overline{-} \cdot 11$ & 7.94 & 0.2 & 10 \\
\hline 50 & 0.092 & 118,654 & $\overline{-} \cdot 05$ & 6.14 & 50 & 0.114 & 132,343 & $\begin{array}{c}- \\
0.06 \\
\end{array}$ & 3.99 & 0.2 & 10 \\
\hline 100 & 0.184 & 164,253 & $\overline{-} 02$ & 3.35 & 100 & 0.229 & 180,598 & $\overline{-} \cdot \overline{0}$ & 2.02 & 0.2 & 10 \\
\hline 120 & 0.221 & 178,149 & $\begin{array}{c}- \\
0.01\end{array}$ & 2.78 & 120 & 0.274 & 194,431 & 0.03 & 1.67 & 0.75 & 30 \\
\hline \multicolumn{5}{|c|}{ Safety factor $=7.5$} & \multicolumn{5}{|c|}{ Safety factor $=6$} & \multicolumn{2}{|r|}{5} \\
\hline \multicolumn{12}{|c|}{$\begin{array}{c}\text { Approximate price of current transformer }=1,160 \text { USD } \\
\text { 3) } \text { maonetic core }(345 \times 437 \times 40 \text { mp) }\end{array}$} \\
\hline \multicolumn{5}{|c|}{ 3) magnetic core $(\mathbf{3 4 5} \times \mathbf{4 3 7} \times \mathbf{4 0} \mathbf{~ m m})$ type } & \multicolumn{5}{|c|}{ Tee off $600 \mathrm{~A}$} & \multicolumn{2}{|c|}{ Request } \\
\hline $\begin{array}{l}\begin{array}{l}I_{1}, \\
\%\end{array} \\
\end{array}$ & $B_{m}, \mathrm{~T}$ & $\mu$ & $\begin{array}{c}\Delta K, \\
\%\end{array}$ & $\begin{array}{c}\delta \\
\min \end{array}$ & $\begin{array}{l}I_{1}, \\
\% \\
\end{array}$ & $B_{m}, \mathrm{~T}$ & $\mu$ & $\begin{array}{c}\Delta K, \\
\%\end{array}$ & $\begin{array}{c}\delta, \\
\min \end{array}$ & $\begin{array}{c}\Delta K, \\
\%\end{array}$ & $\begin{array}{c}\delta, \\
\min \end{array}$ \\
\hline 1 & 0.002 & 76,394 & $0 . \overline{18}$ & 13.50 & 1 & 0.002 & 77,834 & $0 . \overline{17}$ & 10.59 & 1 & 0.002 \\
\hline 5 & 0.010 & 97,506 & $\begin{array}{c}- \\
0.14 \\
\end{array}$ & 10.20 & 5 & 0.012 & 102,374 & $\begin{array}{c}- \\
0.13 \\
\end{array}$ & 7.66 & 5 & 0.010 \\
\hline 20 & 0.040 & 132,906 & $\overline{0} \overline{14}$ & 6.19 & 20 & 0.050 & 145,488 & $0 . \overline{12}$ & 4.11 & 20 & 0.040 \\
\hline 50 & 0.101 & 213,613 & $\begin{array}{c}- \\
0.09\end{array}$ & 2.60 & 50 & 0.124 & 244,811 & $\begin{array}{c}- \\
0.07 \\
\end{array}$ & 1.41 & 50 & 0.101 \\
\hline 100 & 0.201 & 294,551 & $\begin{array}{c}- \\
0.06 \\
\end{array}$ & 1.51 & 100 & 0.249 & 297,904 & $\begin{array}{c}- \\
0.05 \\
\end{array}$ & 1.37 & 100 & 0.201 \\
\hline 120 & 0.241 & 304,224 & $\begin{array}{c}- \\
0.05 \\
\end{array}$ & 1.71 & 120 & 0.298 & 217,699 & $\begin{array}{c}- \\
0.07 \\
\end{array}$ & 2.71 & 120 & 0.241 \\
\hline \multicolumn{5}{|c|}{ Safety factor $=2.5$} & \multicolumn{5}{|c|}{ Safety factor $=3$} & \multicolumn{2}{|c|}{5} \\
\hline
\end{tabular}

The current transformer with the combined magnetic core of the AMET-5V:82V type satisfies all technical requirements according to the initial data.

The current transformer with the magnetic core of the AMET-5V type does not satisfy the measurement accuracy with respect to the angular error (in certain situations, especially for the $0.2 \mathrm{~S}$ accuracy class, the magnetic properties of nanocrystalline iron-based alloys are insufficient [9]), and also does not satisfy the requirement for the maximum safety factor. An increase in the magnetic core section in order to reduce the angular error is impossible, since this will lead to an even greater safety factor.

A current transformer with the magnetic core of the AMET-82V type satisfies all technical requirements according to the initial data. At the same time, the specified requirements can be achieved even with a contraction of the cross-sectional area by $8 \%$. At the same time, the cost of the current transformer with an $82 \mathrm{~V}$ type of magnetic core is $30 \%$ higher than with the combined type of AMET-5V:82V magnetic core, even taking into account the difference in cross-sectional areas of the magnetic cores.

\section{Conclusions}

1. The use of combined magnetic cores allows to design a current transformer that to the fullest extent possible satisfies the technical requirements owing to the selection of the 
effective magnetic properties of the magnetic core using a combination of various magnetic materials.

2. The proposed mathematical model does not require the solution of complex systems of differential equations and the use of specialized software systems, which makes it convenient and quick to use by a wide range of specialists.

3. The appliance of combined magnetic cores allows to reduce significantly the final cost of current transformers, due to the decline in the use of expensive magnetic materials, for example, on basis of cobalt. Thus, their properties are used only in the area of the required accuracy class where it is necessary, excluding an overabundance of magnetic characteristics, which provides a rational production model.

4. The use of combined magnetic cores is especially actual in relation to the measuring accuracy classes with the prefix "S" $-0.2 \mathrm{~S}$ and $0.5 \mathrm{~S}$, since they impose the most severe requirements, $20 \%$ off the nominal primary current $I_{1}$.

\section{References}

1. Current Transformers - General Technical Specifications (2016)

2. Instrument Transformers - Part 2: Additional Requirements for Current Transformers (2012)

3. C. Swieboda, J. Walak, M. Soinski, et al., Measurement, 136, 50 (2019)

4. W. Pluta, C. Swieboda, J. Leszczynski, M. Soinski, Measurement, 97, 38 (2017)

5. E. Lesniewska, R. Rajchert, IET Science, Measurement \& Technology (2019)

6. E. E. Lesniewska, R. Rajchert, IEEE Transactions on Magnetics, 46 (10), 3778 (2010)

7. J. D. Duan, H. Li, Y. Lei, Int. J. Electr Power Energy Syst, 105, 315 (2019)

8. P. Sergeant, L. Dupre, IEEE Trans. Magn., 45(2), 678 (2009)

9. T. C. Batista, B. A. Luciano, R. C. S. Freire, et al., J. Alloys Compd., 615, 228 (2014) 